\title{
Prevalence and pattern of torus palatinus and torus mandibularis among edentulous patients of Saudi Arabia
}

\author{
Bader K AIZarea \\ Department of Prosthodontics, \\ College of Dentistry, Al Jouf \\ University, Al Jouf, Kingdom \\ of Saudi Arabia
}

This article was published in the following Dove Press journal:

Clinical Interventions in Aging

24 February 2016

Number of times this article has been viewed

Background: The most remarkable exostoses of the human jaws are torus palatinus (TP) and torus mandibularis (TM). The aim of the present study was to actuate the prevalence of TP and TM in relation to age and sex among the edentulous patients of Saudi Arabia.

Methods: The present study included 847 edentulous subjects (458 men and 389 women) aged between 51 and 79 years. The subjects were examined for the existence of tori by clinical inspection and palpation. Statistical analysis was performed using SPSS for Windows version.

Results: Among the 847 subjects, 149 (17.59\%) had either TP or TM. Sixty six (7.79\%) subjects had TP, whereas $83(9.80 \%)$ had TM. The maximum percentage $(36.36 \%)$ of tori was observed in the age-group of 60-69 years. The percentage of males with either tori was higher $(19.0 \%)$ when compared to females (15.94\%). According to shape, the occurrence of flat-shaped TP (57.58\%) and bilateral solitary TM (39.76\%) was more common.

Conclusion: No significant difference in the presence of tori with respect to sex and age was observed. A comparatively increased prevalence of TP and TM was however observed, and this should be taken into consideration while planning for prosthodontic and periodontal therapy in these patients.

Keywords: edentulous, prevalence, torus mandibularis, torus palatinus

\section{Introduction}

The tori are benign anatomical bony protuberances, also termed as exostosis. They are composed of dense cortical bony structure and minimal amount of bone marrow, and are covered with a fragile and limited vascularized mucosa. Tori usually become apparent during the second or third decade of life. ${ }^{1}$ Tori may develop at the midline of palate (torus palatinus [TP]) or the lingual aspect of the mandible (torus mandibularis [TM]). Jaw exostosis at any other location has no precise designation and may be seen as a bony protrusion on the buccal aspect of the maxilla and mandible or palatal aspect of the maxilla. ${ }^{2}$

TP may be defined as an exostosis of the hard palate located along the median palatine suture, involving both the processi palatini and the os palatinum. ${ }^{3} \mathrm{TM}$ is observed as a bony protuberance on the lingual surface of the mandible, which is situated mostly in the canine and the premolar region, above the mylohyoid ridge. ${ }^{4}$ According to the shape, TP can be classified as flat, spindle-shaped, nodular, and lobular, whereas TM can be classified as unilateral and bilateral solitary, unilateral and bilateral multiple, and bilateral combined..$^{5}$ The size of TP is highly variable, varying from that of a small pea to an enormous enlargement that may cover the entire palate to the extent 
of occlusal plane. Reichart et al have classified TP, based on their size, as small (less than $3 \mathrm{~mm}$ ), medium (3-6 mm), and large (more than $6 \mathrm{~mm}$ ) tori. ${ }^{6} \mathrm{TM}$ may also show variation in size, but is usually small in size.

Till date, no exact etiology has been identified for the presence of tori. The most widely accepted theory today is that that this condition has a multifactorial etiology, which includes mainly genetics and environmental factors. ${ }^{5}$ Many predisposing factors such as trauma, drugs, discontinued growth, infection, masticatory stress, and environmental and nutritional factors have been identified by various researchers. ${ }^{1,6-8}$ According to a study by Eggen et al, ${ }^{9}$ who investigated the influence of nutrients in the etiology of tori, dietary components also seem to play a role in the prevalence of tori. It was suggested that consumption of saltwater fish in Norway is possibly responsible for supplying increased amounts of polyunsaturated fatty acids and vitamin D, which is associated with growth of the bone, and this may escalate the prevalence of tori. ${ }^{9}$

Till date, no study has been carried out to estimate the prevalence of TP and TM with respect to age-group and sex among the edentulous subjects of Saudi Arabia.

\section{Methods}

Ethical approval was obtained from the College of Dentistry, Aljouf University. Written informed consent was taken from all the participants included in the study. The present study comprised 847 edentulous subjects (458 men and 389 women) aged between 51 and 79 years and were selected using the convenience sampling method. The present prospective, descriptive study was carried out at the College of Dentistry, Aljouf University of Saudi Arabia, from June 2012 to May 2015. Subjects were categorized based on their sex and were classified into four age-groups, namely 51-59, 60-69, 70-79, and 80-89 years. The existence of tori was determined by clinical examination and palpation, and result of the test was recorded as present or absent. Changes in the middle part of the palate were analyzed and were recorded as flat, spindle-shaped, nodular, or lobular tori. TM was observed in the sublingual part of the mandible and recorded as unilateral solitary, bilateral solitary, unilateral multiple, bilateral multiple, or bilateral combined. Patients with questionable tori were excluded from the study. The data were collected and entered into SPSS 12.0 (SPSS Inc., Chicago, IL, USA) software program for Windows version. The statistical analysis was performed using chi-square $\left(\chi^{2}\right)$ test and $P$-value at $5 \%$ level was considered to be statistically significant.

\section{Results}

Table 1 reveals that out of a total of 847 subjects, $149(17.59 \%)$ had prevalence of either tori. Sixty-six subjects (7.79\%) had TP and 83 (9.80\%) had TM. No association was observed between the location of tori and $\operatorname{sex}\left(\chi^{2}=0.0243, P=0.8773\right)$ at $5 \%$ level of significance. This signified that males and females had similar prevalence of TP and TM. Table 2 represents the distribution of TP and TM with respect to age and sex. Out of the 66 subjects with TP, maximum number of males $(15,35.46 \%)$ belonged to the age-group 60-69 years and minimum (five, $12.82 \%$ ) to the age-group 50-59 years. However, a maximum of nine females $(33.33 \%)$ belonged to the age-group 60-69 years and minimum (five, $18.52 \%$ ) to the age-group 80-89 years. No association was observed between males and females in different age-groups with respect to the occurrence of TP $\left(\chi^{2}=1.8762, P=0.5984\right)$. Out of the 83 subjects with TM, a maximum of 14 males $(29.17 \%)$ belonged to the age-group 70-79 years and minimum (ten, 20.83\%) to the age-group 50-59 years. However, a maximum of 13 females $(37.14 \%)$ belonged to the age-group 50-59 years and minimum (six, 17.14\%) to the age-group 80-89 years. No difference was observed between males and females in different age-groups with respect to the occurrence of TM $\left(\chi^{2}=2.0628, P=0.5584\right)$. Table 3 presents the distribution of TP according to shape. Out of the 66 subjects, 38 (57.58\%) presented with flat tori, $15(22.73 \%)$ with spindle-shaped tori, nine $(13.64 \%)$ with nodular-shaped tori, and four $(6.06 \%)$ with lobular-shaped tori. The sex-wise distribution clearly shows that statistically significant difference was observed between male and female subjects with regard to the status of TP $\left(\chi^{2}=0.8631, P=0.8354\right)$.

Table 4 presents the distribution of TM according to shape. Out of the 83 subjects, 33 (39.76\%) had bilateral and solitary TM, $23(27.71 \%)$ unilateral and solitary TM, 14 (16.87\%) unilateral and multiple TM, nine (10.84\%) bilateral and multiple TM, and four $(4.82 \%)$ bilateral combined TM. Sex-wise difference in the distribution was observed between male and female subjects with regard to the status of TM $\left(\chi^{2}=0.8631, P=0.8354\right)$.

Table I Prevalence of tori in the study population according to location

\begin{tabular}{lllllll}
\hline Location & $\begin{array}{l}\text { Male } \\
(\mathbf{n = 4 5 8 )}\end{array}$ & $\%$ & $\begin{array}{l}\text { Female } \\
(\mathbf{n = 3 8 9})\end{array}$ & & $\begin{array}{l}\text { Total } \\
(\mathbf{n}=\mathbf{8 4 7})\end{array}$ & $\%$ \\
\hline Torus palatinus & 39 & 8.52 & 27 & 6.94 & 66 & 7.79 \\
Torus mandibularis & 48 & 10.48 & 35 & 9.00 & 83 & 9.80 \\
Total & 87 & 19.00 & 62 & 15.94 & 149 & 17.59 \\
$\chi^{2}=0.0243, P=0.8773$ & & & & & & \\
\hline
\end{tabular}


Table 2 Distribution of torus palatinus and torus mandibularis according to age and sex

\begin{tabular}{|c|c|c|c|c|c|c|}
\hline \multirow[t]{2}{*}{ Age-groups (years) } & \multicolumn{3}{|c|}{ Torus palatinus } & \multicolumn{3}{|c|}{ Torus mandibularis } \\
\hline & Male n (\%) & Female $\mathrm{n}(\%)$ & Total n (\%) & Male n (\%) & Female n (\%) & Total n (\%) \\
\hline $50-59$ & $5(12.82)$ & $7(25.93)$ & $12(18.18)$ & II (22.92) & $13(37.14)$ & $24(28.92)$ \\
\hline $60-69$ & $15(38.46)$ & $9(33.33)$ & $24(36.36)$ & $13(27.08)$ & $7(20.00)$ & $20(24.10)$ \\
\hline 70-79 & II (28.2I) & $6(22.22)$ & $17(25.76)$ & $14(29.17)$ & $9(25.7 \mathrm{I})$ & $23(27.71)$ \\
\hline $80-89$ & $8(20.5 \mathrm{I})$ & $5(18.52)$ & $13(19.70)$ & $10(20.83)$ & $6(17.14)$ & $16(19.28)$ \\
\hline Total & $39(100.00)$ & $27(100.00)$ & $66(100.00)$ & $48(100.00)$ & $35(100.00)$ & $83(100.00)$ \\
\hline \multicolumn{4}{|l|}{$\chi^{2}=1.8762, P=0.5984$} & \multicolumn{3}{|c|}{$\chi^{2}=2.0628, P=0.5584$} \\
\hline Mean & 71.14 & 68.83 & 70.20 & 70.29 & 67.79 & 69.23 \\
\hline SD & 9.55 & 10.54 & 10.03 & 10.64 & 11.28 & 10.99 \\
\hline
\end{tabular}

Abbreviation: SD, standard deviation.

\section{Discussion}

Tori are nodular protuberances that are composed of mature bone, the exact designation of which depends on their anatomic position. These are usually considered an anatomical variation rather than a pathological entity. Although tori are not considered to be pathologically significant, surgical removal is indicated in cases where they may cause chronic trauma or interfere with the function of oral cavity, or when there is a need for the replacement of a denture base or its framework. ${ }^{3}$ The size of the tori can change throughout life, and may range from a few millimeters to centimeters. An increase in size may be observed in the early adulthood, but it may show a decrease in size in the older age-group due to bone resorption.

The prevalence rates of TP and TM diversify in populations with contrasting ethnic origins from $0 \%$ to $66 \%$ and from $0 \%$ to $85.7 \%$, respectively., ${ }^{2,10,11}$ Significant racial differences have also been observed with Mongoloids having a higher prevalence rate than Caucasians, and Caucasians having a higher prevalence rate than blacks. ${ }^{12,13}$ The prevalence of tori is currently unknown in the Arab ethnic group. However, Salem et al reported a $1.4 \%$ frequency of TP in 6-12-year-old Saudi school children, and Yildiz et al reported a $30.9 \%$ prevalence rate of TP in 5-15-year-old Turkish school children. ${ }^{11,14}$ However, we believe that this could be an underestimation of the prevalence of tori in this population, since loss of teeth has been reported to alter alveolar

Table 3 Distribution of torus palatinus according to shape

\begin{tabular}{lllllll}
\hline Shape & Male & $\%$ & Female & $\%$ & Total & $\%$ \\
\hline Flat & 22 & $56.4 \mathrm{I}$ & 16 & 59.26 & 38 & 57.58 \\
Spindle & 8 & $20.5 \mathrm{I}$ & 7 & 25.93 & 15 & 22.73 \\
Nodular & 6 & 15.38 & 3 & $11.1 \mathrm{I}$ & 9 & 13.64 \\
Lobular & 3 & 7.69 & $\mathrm{I}$ & 3.70 & 4 & 6.06 \\
Total & 39 & 100.00 & 27 & 100.00 & 66 & 100.00 \\
$\chi^{2}=0.863 \mathrm{I}, P=0.8354$ & & & & & \\
\hline
\end{tabular}

bone metabolism and to influence the prevalence of tori. ${ }^{2}$ This is the pioneer research to address the prevalence of TP and TM in edentulous subjects of Saudi Arabia. Results of this study revealed an increased prevalence of TP and TM $(17.5 \%)$ in comparison to the studies previously reported in the literature: $12.3 \%$ among Trinidad and Tobago West Indian population, $6.6 \%$ in Jamaican blacks, $13.9 \%$ in Jordanian population, $14.2 \%$ in Norwegians, and $14.6 \%$ in Ghanaian community. ${ }^{9,15-18}$

It has been reported that TP occurs more frequently thanTM. In contrast to this, the results of the present study showed higher prevalence of TM $(9.8 \%)$ in comparison to TP (7.79\%). This finding is similar to that of Sirirungrojying and Kerdpon and Bruce et al who noticed a higher prevalence of TM than that of TP. ${ }^{17,19} \mathrm{Al}$ Quran and Al-Dwairi, while studying the prevalence of TP and TM in 338 edentulous Jordanian patients, reported prevalence rates of $29.8 \%$ for TP and $42.6 \%$ for TM, which was much higher than the findings of the present study. ${ }^{18}$ Salem et al reported no cases of TM and a very low prevalence rate (1.4\%) of TP at Gizan region, Saudi Arabia, in comparison to the observation of the present study.$^{14}$ The incidence of TM among North Americans and African-Americans (33.8\%) were high, whereas Caucasians (22.8\%) were more likely to present TP. ${ }^{20}$ In analyzing the incidence among Norwegians, we found two studies that yielded different results. In the first study, the percentage of

Table 4 Distribution of torus mandibularis according to shape

\begin{tabular}{lllllll}
\hline Shape & Male & $\%$ & Female & $\%$ & Total & $\%$ \\
\hline Unilateral solitary & 14 & 29.17 & 9 & 25.71 & 23 & 27.71 \\
Bilateral solitary & 18 & 37.50 & 15 & 42.86 & 33 & 39.76 \\
Unilateral multiple & 8 & 16.67 & 6 & 17.14 & 14 & 16.87 \\
Bilateral multiple & 5 & 10.42 & 4 & 11.43 & 9 & 10.84 \\
Bilateral combined & 3 & 6.25 & $\mathrm{I}$ & 2.86 & 4 & 4.82 \\
Total & 48 & 100.00 & 35 & 100.00 & 83 & 100.00 \\
$\chi^{2}=0.7386, P=0.9475$ & & & & & \\
\hline
\end{tabular}


TP was 9.22\%, whereas in the second study, TP was observed to be $36.1 \%$, and TM was observed to be $7.23 \%$ and $18.8 \%$, respectively, which were higher in comparison to the results obtained in the present study. ${ }^{7,9}$ Similar contrasting results were also observed in two other studies in Thailand. In the first study, the percentage of TP was $23.1 \%$, and in the second study, it was $58 \%$, whereas the incidence of TM was $9.2 \%$ and $33 \%$, respectively. ${ }^{6,19}$

TP is observed to be most prevalent in females in comparison to males, and this was attributed to a dominant type, $\mathrm{X}$ chromosome. ${ }^{21}$ However, the present study showed contrasting results, where TP was more prevalent in male subjects, similar to the findings of Patil et al and Sonnier et al. ${ }^{8,20}$ TM was reported to be more prevalent in males and this was similar to the findings of this study. Some authors have also found no significant differences in the prevalence of TM between males and females. ${ }^{22}$ The results of the current research did not reveal any compelling diversity in prevalence of either TP or TM between males and females, entailing that the sex-based factor has minimal impact on the prevalence of tori.

The researches in the past have suggested that the incidence of tori is related to the age difference., ${ }^{4,12,23}$ Earlier studies have revealed higher prevalence rates of TP during the second and third decades of life, and few suggest that highest prevalence rate is observed during the fifth decade. ${ }^{5,7}$ Similar findings were observed in the present study, where the highest prevalence of tori was observed in the age-group of 60-69 years. The presence of tori is related to the increasing age as suggested by Jainkittivong et al and Al Quran and Al-Dwairi. ${ }^{18,23}$ No significant relationship between age and existence of tori was observed in the present study, which was similar to the findings of Chohayeb and Volpe. ${ }^{24}$

According to the shape, TP can be classified as flat, spindle-shaped, nodular, and lobular, whereas TM can be classified as unilateral and bilateral solitary, unilateral and bilateral multiple, and bilateral combined. The flat-shaped tori $(57.58 \%)$ were reported to be more commonly seen in the present study, followed by spindle-shaped tori $(22.73 \%)$. This finding is in line with other similar studies mentioned in the literature. ${ }^{8,15,16}$ However, Simunković et al, Jainkittivong et al, and Reichart et al showed a higher prevalence of spindle-shaped tori. ${ }^{5,6,23}$ Haugen found that nodular TP was core common. ${ }^{7}$ Bilateral solitary type of TM was most commonly observed in this study, which was similar to the observations by Reichart et al, Patil et al, and Sonnier et al., ${ }^{6,20}$

Tori were reported to be associated with masticatory dysfunction, speech disturbances, oral ulcerations, cancerophobia, parafunctional activity, etc..$^{9,21}$ This research did not include any studies on significant clinical medical conditions or associated dental anomalies in relation to tori. Correlation between TP and TM and chronic phenytoin administration was reported by Sasaki et al. ${ }^{25}$ Tori were also known to be associated with other dental anomalies such as exostosis, unerupted and impacted tooth, mandibular canines, and sclerosteosis. ${ }^{17,22}$ The prevalence and degree of expression of tori might be related to the masticatory demand that increases with increasing age, and possibly, subsides after the fifth decade of life due to reduction in the number of teeth. ${ }^{19}$

The size, shape, and location of TP and TM are the significant factors for prosthodontic considerations in these patients. Medium to large variants of TP and TM, and the premolar-molar location substantiates the need for modification of the design or surgical intervention before any removable partial dentures can be constructed. Spindle and flat variants of TP are considered to pose less potential for prosthodontic complications, compared to the nodular form. The bilateral nature of most cases of TM would impose more challenge toward prosthodontic treatment, where the crossarch stability should be sought. ${ }^{18}$

Tori are usually an asymptomatic clinical finding that do not normally require treatment. It is possible for ulcers to form on the area of the tori due to repeated trauma. However, the existence of tori may be beneficial as they may serve as ground for harvesting bone for augmenting the ridge in cases of replacing a missing tooth and the TP and TM can be adopted as antecedents of autogenous cortical bone in periodontal surgery. TM might be useful as an indicator for increased risk of temporomandibular disorders in some patients. ${ }^{18,24}$

\section{Conclusion}

The results of the present study show that the prevalence of tori in the Arabian population is low and the incidence of tori is higher in males when compared to females, which is however not significant. There is a trend toward higher prevalence of tori with increasing age, although not significant. Further long-term prospective studies are encouraged for future assessment of the prevalence of TP and TM in this region. Treatment is not indicated for unless 1 ) they enlarge to a huge size and hinder the normal functions, 2) there is a need for replacement of denture, or 3 ) the patients suffer from repeated ulcerations. Long-term prospective cohort studies are recommended to further assess the prognostic factors and survival rates of TP and TM in Saudi Arabian population. 


\section{Disclosure}

The author reports no conflicts of interest in this work.

\section{References}

1. Al-Sebaie D, Alwrikat M. Prevalence of torus palatinus and torus mandibularis in Jordanian population. Pak Oral Dent J. 2011;31: 214-216.

2. Sawair FA, Shayyab MH, Al-Rababah MA, Saku T. Prevalence and clinical characteristics of tori and jaw exostoses in a teaching hospital in Jordan. Saudi Med J. 2009;30:1557-1562.

3. Sisman Y, Ertas ET, Gokce C, Akgunlu F. Prevalence of torus palatinus in cappadocia region population of Turkey. Eur J Dent. 2008;2: 269-275.

4. Axelsson G, Hedegård B. Torus mandibularis among Icelanders. Am J Phys Anthropol. 1981;54:383-389.

5. Simunković SK, Bozić M, Alajbeg IZ, Dulcić N, Boras VV. Prevalence of torus palatinus and torus mandibularis in the Split-Dalmatian County, Croatia. Coll Antropol. 2011;35:637-641.

6. Reichart PA, Neuhaus F, Sookasem M. Prevalence of torus palatinus and torus mandibularis in Germans and Thais. Commun Dent Oral Epidemiol. 1988;16:61-64.

7. Haugen LK. Palatine and mandibular tori. A morphologic study in the current Norwegian population. Acta Odontol Scand. 1992;50:65-77.

8. Patil S, Maheshwari S, Khandelwal SK. Prevalence of torus palatinus and torus mandibularis in an Indian population. Saudi J Oral Sci. 2014; 1:94-97.

9. Eggen S, Natvig B, Gåsemyr J. Variation in torus palatinus prevalence in Norway. Scand J Dent Res. 1994;102:54-59.

10. Pechenkina EA, Benfer RA Jr. The role of occlusal stress and gingival infection in the formation of exostoses on mandible and maxilla from Neolithic China. Homo. 2002;53:112-130.

11. Yildiz E, Deniz M, Ceyhan O. Prevalence of torus palatinus in Turkish school children. Surg Radiol Anat. 2005;27:368-371.

12. Kerdpo D, Sirirungrojying S. A clinical study of oral tori in Southern Thailand: prevalence and the relation to parafunctional activity. Eur J Oral Sci. 1999;107:9-13.
13. Agbaje JO, Arowojolu MO, Kolude N, Lawoyin JO. Torus palatinus and torus mandibularis in a Nigerian population. Afr J Oral Health. 2005;2:30-36.

14. Salem G, Holm SA, Fattah R, Basset S, Nasser C. Developmental oral anomalies among school children in Gizan region, Saudi Arabia. Community Dent Oral Epidemiol. 1987;15:150-151.

15. Al-Bayaty HF, Murti PR, Matthews R, Gupta PC. An epidemiological study of tori among 667 dental outpatients in Trinidad and Tobago, West Indies. Int Dent J. 2001;51:300-304.

16. King DR, King AR. Incidence of tori in 3 population groups. J Oral Med. 1981;36:21-23.

17. Bruce I, Ndanu TA, Addo ME. Epidemiological aspects of oral tori in a Ghanaian community. Int Dent J. 2004;54:78-82.

18. Al Quran FAM, Al-Dwairi ZN. Torus palatinus and torus mandibularis in edentulous patients. J Contemp Dent Pract. 2006;7:112-119.

19. Sirirungrojying S, Kerdpon D. Relationship between oral tori and temporomandibular disorders. Int Dent J. 1999;49:101-104.

20. Sonnier KE, Horning GM, Cohen ME. Palatal tubercles, palatal tori, and mandibular tori: prevalence and anatomical features in a U.S. population. J Periodontol. 1999;70:329-336.

21. García-García AS, Martínez-González JM, Gómez-Font R, SotoRivadeneira A, Oviedo-Roldán L. Current status of the torus palatinus and torus mandibularis. Med Oral Patol Oral Cir Bucal. 2010;15: e353-e360.

22. Martínez-González JM. Benign tumors of the maxilla. In: Donado M, editor. Cirugía Bucal. Patología y Técnica. 2nd edn. Barcelona: Masson; 1998:627-639.

23. Jainkittivong A, Apinhasmit W, Swasdison S. Prevalence and clinical characteristics of oral tori in 1,520 Chulalongkorn University Dental School patients. Surg Radiol Anat. 2007;29:125-131.

24. Chohayeb AA, Volpe AR. Occurrence of torus palatinus and mandibularis among women of different ethnic groups. Am J Dent. 2001; 14:278-280.

25. Sasaki H, Ikedo D, Kataoka M, Kido J, Kitamura S, Nagata T. Pronounced palatal and mandibular tori observed in a patient with chronic phenytoin therapy: a case report. J Periodontol. 1999;70:445-448.
Clinical Interventions in Aging

\section{Publish your work in this journal}

Clinical Interventions in Aging is an international, peer-reviewed journal focusing on evidence-based reports on the value or lack thereof of treatments intended to prevent or delay the onset of maladaptive correlates of aging in human beings. This journal is indexed on PubMed Central, MedLine,

\section{Dovepress}

CAS, Scopus and the Elsevier Bibliographic databases. The manuscript management system is completely online and includes a very quick and fair peer-review system, which is all easy to use. Visit http://www.dovepress. $\mathrm{com} /$ testimonials.php to read real quotes from published authors. 